Peter Viebahn, Daniel Vallentin, Samuel Höller, Manfred Fischedick

\title{
Integrated Assessment of CCS in the German Power Plant Sector with special Emphasis on the Competition with Renewable Energy Technologies
}

Originally published as:

Peter Viebahn, Daniel Vallentin, Samuel Höller, Manfred Fischedick (2012):

Integrated Assessment of CCS in the German Power Plant Sector with special Emphasis on the Competition with Renewable Energy Technologies In: Mitigation and Adaptation Strategies for Global Change 17(6)707-730 
Peter Viebahn ${ }^{a,{ }^{*}}$, Daniel Vallentin ${ }^{\text {a }}$, Samuel Höller ${ }^{\text {a }}$, Manfred Fischedick ${ }^{a}$

\section{Integrated Assessment of CCS in the German Power Plant Sector with special Emphasis on the Competition with Renewable Energy Technologies}

a Wuppertal Institute for Climate, Environment and Energy, Germany

*Corresponding author: Peter Viebahn, Wuppertal Institute, Döppersberg 19, 42103 Wuppertal, Germany

E-mail: peter.viebahn@wupperinst.org

Phone: +49-202-2492306

Fax: $\quad+49-202-2492198$ 


\begin{abstract}
The study presents the results of an integrated assessment of carbon capture and storage (CCS) in the power plant sector in Germany, with special emphasis on the competition with renewable energy technologies. Assessment dimensions comprise technical, economic and environmental aspects, long-term scenario analysis, the role of stakeholders and public acceptance and regulatory issues. The results lead to the overall conclusion that there might not necessarily be a need to focus additionally on CCS in the power plant sector. Even in case of ambitious climate protection targets, current energy policy priorities (expansion of renewable energies and combined heat and power plants as well as enhanced energy productivity) result in a limited demand for CCS. In case that the large energy saving potential aimed for can only partly be implemented, the rising gap in $\mathrm{CO}_{2}$ reduction could only be closed by setting up a CCS-maximum strategy. In this case, up to 22 per cent $(41 \mathrm{GW})$ of the totally installed load in 2050 could be based on CCS. Assuming a more realistic scenario variant applying CCS to only $20 \mathrm{GW}$ or lower would not be sufficient to reach the envisaged climate targets in the electricity sector. Furthermore, the growing public opposition against $\mathrm{CO}_{2}$ storage projects appears as a key barrier, supplemented by major uncertainties concerning the estimation of storage potentials, the long-term cost development as well as the environmental burdens which abound when applying a life-cycle approach.
\end{abstract}

However, recently, alternative applications are being increasingly considered - that is the capture of $\mathrm{CO}_{2}$ at industrial point sources and biomass based energy production (electricity, heat and fuels) where assessment studies for exploring the potentials, limits and requirements for commercial use are missing so far. Globally, CCS at power plants might be an important climate protection technology: coal-consuming countries such as China and India are increasingly moving centre stage into the debate. Here, similar investigations on the development and the integration of both, CCS and renewable energies, into the individual energy system structures of such countries would be reasonable.

Keywords: CCS, Germany, global, integrated assessment, power plant, renewable energy

\title{
1. Introduction
}

In April 2009, the European Union (EU) adopted a so-called CCS Directive, which defines guidelines for the provision of regulatory frameworks for underground $\mathrm{CO}_{2}$ storage in the EU member states. Requiring the member states to translate these guidelines into national law until June 2011, the Directive has in many EU countries provoked controversial debates on the pros and cons of the CCS (carbon capture and storage) technology.

In Germany, the decision-making process for a national law for underground $\mathrm{CO}_{2}$ storage has gained a particularly high degree of public attention as the country is pursuing ambitious $\mathrm{CO}_{2}$ mitigation targets of minus 40 per cent until 2020 and at least minus 80 to 95 per cent until 2050 (both compared to 1990 levels) but at the same time being the EU's largest coal producer, with about 44 per cent of its electricity supply coming from coal-fired power plants (BMWi 2010). Before 2009, the set of stakeholders involved in the German CCS debate was limited to experts 
from industry, federal ministries and parties, environmental NGOs and scientists (WI et al. 2007). The debate on the national CCS law has significantly expanded the range of stakeholders involved in the CCS discussion and led to a more differentiated and informed public discourse. This trend was sustained and strengthened by initial exploration activities of German utilities at potential $\mathrm{CO}_{2}$ storage sites which aroused strong opposition by the local population.

The heated CCS debate calls for a profound and integrated scientific analysis which takes into account all dimensions affecting the deployment of the CCS technology in Germany - including "hard" and "soft" aspects. "Hard" aspects encompass technical, economic and environmental parameters of $\mathrm{CCS}$, the available national $\mathrm{CO}_{2}$ storage capacity as well as a long-term scenario analysis of the technology's potential in Germany. "Soft" aspects comprise the role of stakeholders and public acceptance and the regulatory framework for CCS in Europe and Germany.

The Wuppertal Institute for Climate, Environment and Energy together with other research organisations have presented a first integrated assessment of CCS for Germany in 2007 which compared the technology's potential with renewable energy technologies (WI et al. 2007). Due to both, a growing critical public discussion on CCS and ambitious national and European renewable energy targets set in the EU's "green package" at the end of 2008, the Institute was assigned by the German Federal Ministry for the Environment, Nature Conservation and Nuclear Safety to update and to enhance this study with focus on the power plant sector (WI 2010).

The presented paper firstly goes through the individual assessment aspects of the study, for each one showing the objective, the applied methodology and the results (section 2). Secondly, the authors combine the assessment dimensions to present an overall result from an integrated perspective and to recommend where and how to proceed in the current CCS debate (section 3). The paper closes with final conclusion and an outlook on the needs for future research (section 4).

\section{Integrated Assessment of CCS in the Power Plant Sector in Germany}

\subsection{Overall methodology and assessment dimensions}

The integrated assessment approach chosen for the assessment of CCS in this paper is based on the notion that technologies are complex and dynamic systems which do not merely consist of techno-economic factors but are also shaped by social parameters, such as political and interpersonal aspects (McLoughlin and Dawso 2003). Therefore an assessment is necessary that takes into account both technical ("hard") and non-technical ("soft") issues, looks dynamically into the future and considers stakeholder perspectives. Such an integrated assessment approach which involves a critical and objective analysis of a problem domain while integrating the knowledge from different perspectives and making it available for societal learning and decision making processes (TIAS 2011).

The individual methodologies used in our analysis include scenario analysis, levelised electricity generation cost calculation, life-cycle assessment and top-down storage capacity modelling in case of "hard" dimensions as well as literature analysis, expert meetings, reviews of position papers, cluster analysis and legislative analysis in case of "soft" dimensions. Furthermore, in case of power production cost, life cycle assessment and scenario analysis CCS based power plants are compared to 
renewable electricity generation. The specific scientific methods applied for each dimension will be elucidated in more detail in the concerned sections.

\subsection{Stakeholder positions}

\subsubsection{Objective and methodology}

This section addresses the actor-related dimension of the CCS system and sketches a constellation of stakeholders on CCS in Germany. The stakeholder analysis includes stakeholders, which are vocal in the German CCS debate and articulate their position in the public. Therefore, Wuppertal Institute systematically analysed the media coverage on CCS in Germany in the course of the year 2009 and screened available position papers and reports by relevant stakeholders. The aim of this process was (1) to identify relevant stakeholders and (2) to find out their position on CCS and arguments used for substantiating this position. As the stakeholder analysis is only one element of the integrated assessment in the presented study, conducting research interviews with the identified stakeholders was beyond the scope of this analysis.

For reasons of comparison and aggregation, the stakeholders were clustered into the following categories: politics, advisory bodies, industry, NGOs, associations and church organisations. In order to limit the number of stakeholders to be covered, individual companies, such as the operators of coal-fired power plants and coalmining companies, are represented by the corresponding industry associations, such as BDEW (Federal Associate of German Energy and Water Utilities) or DEBRIV (German Lignite Industry Association).

The German science sector also plays an important role in the German CCS debate reaching beyond the provision of a knowledge base. Instead, some scientists seem to take position for or against CCS. For the global level, this trend was recognised and criticised by (de Coninck 2010). Nonetheless, scientific bodies or institutes are excluded from the stakeholder analysis below at it is difficult to distinguish between purely informing public statements of scientists and their position on CCS.

\subsubsection{Outcomes}

In recent years, the number of players involved in the German public debate on CCS has steadily grown. In 2007, mainly utility companies and environmental organisations were involved in the public debate, and it was given only brief coverage in the media. Today, the issue ignites diverse debates across a whole spectrum of social, economic and political groups.

The topics on CCS technologies now being debated are much more focused. While in 2007 discussions mainly addressed the technical and economic feasibility of the technology, there is now much broader and more open exchange on the topic, involving advanced aspects such as potential competitive usages with other technologies and liability issues. Furthermore, it is noticeable that greater attention is now being paid to CCS at large industrial plants as an option to reduce process emissions. The technology is also being mentioned more frequently in the context of biomass use and considered as an opportunity for technology exports to emerging economies such as China or India.

The opinions and attitudes on the subject of CCS are strongly divided between its opponents and supporters, sometimes even within the same clusters of stakeholders (for instance, environmental NGOs and science), as illustrated in Figure 1. The 
illustration shows that there is no clear majority among environmental and climate protection organisations either for or against CCS technologies. The relevant industry associations and trade unions, however, are mainly in favour of continuing to explore and implement CCS technologies.

The majority of parties represented in the Bundestag and the German government support the use of CCS. However, at federal state level, Schleswig-Holstein federal state government and all parties represented in the parliament of Schleswig-Holstein, where most potential storage sites are located, clearly oppose the storage of $\mathrm{CO}_{2}$. This policy course is driven by fierce opposition from local communities and citizens' groups in the potential storage regions.

Highly industrialised, coal-producing federal states, such as Brandenburg and North Rhine-Westphalia, on the other hand, are advocates of CCS. A two-level conflict is therefore emerging: at the first level, between federal states with a great $\mathrm{CO}_{2}$ storage potential and the German government and, at the second level, between the "storage states" and all other federal states.

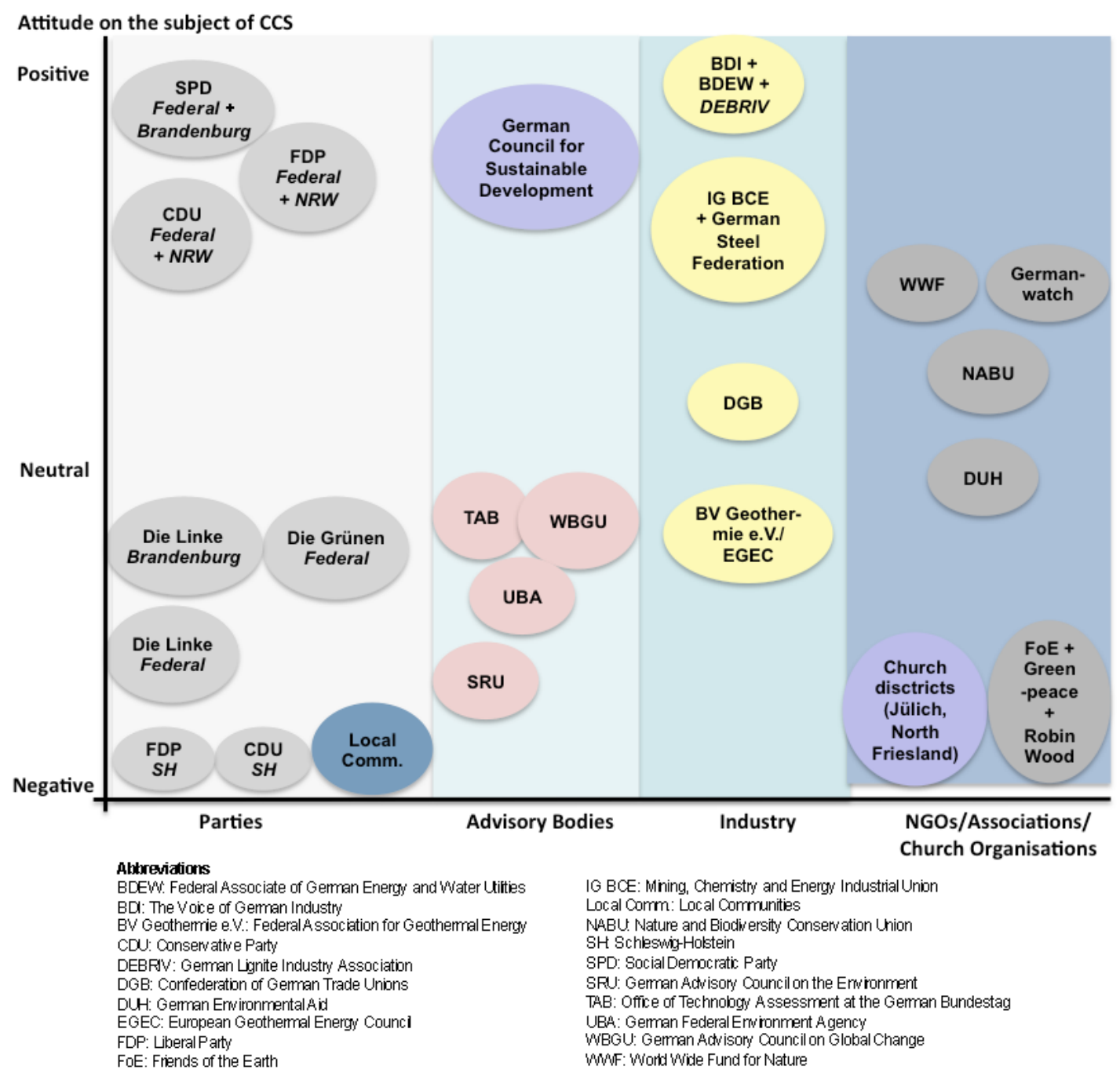

Figure 1: Overview of attitudes of relevant stakeholders on the subject of CCS in Germany 
The positions of advisory committees to the German government towards CCS are mixed. Some of them, such as TAB (Office of Technology Assessment at the German Bundestag) or WBGU (German Advisory Council on Global Change), have a rather neutral attitude towards CCS. Others, like the UBA (Federal Environment Agency) or SRU (Advisory Council on the Environment), take a more negative position. The latter highlight the major uncertainties associated with the use of the technology, in particular its storage, and warn against premature strategic decisions being taken. On the other hand, the German Council for Sustainable Development advocates CCS to facilitate the sustainable use of coal.

\subsection{Legal aspects of introducing CCS to power plant technology}

\subsubsection{Objective and methodology}

The legal framework for CCS is mainly developed at two decision-making levels: the European (EU) level and at the national level of the EU members states. In the following, key points of the process of translating the European CCS Directive into German legislation are discussed and analysed.

\subsubsection{Outcomes}

The European Union has adopted a Directive for carbon capture and storage adopted in April 2009. European member states are obligated to transpose the Directive into national law by June 2011 (see WI 2010 for a detailed analysis and discussion of the EU Directive for CCS). First drafts for a German CCS law were rejected in summer 2009 and 2010 mainly because of concerns about public acceptance and over powers of intervention in the property of third parties.

In April 2011, the governing coalition of the conservative party (CDU/CSU) and the liberal party (FDP) adopted a new draft CCS law (BMU 2011) which implies a more cautious approach towards CCS, being strongly inspired by concerns of the local population in potential storage regions. Taking into account uncertain environmental impacts of underground $\mathrm{CO}_{2}$ storage, the new draft law preliminarily limits $\mathrm{CO}_{2}$ storage operations to pilot and demonstration scale. The annual amount of $\mathrm{CO}_{2}$ injected per storage formation must not exceed 3 million tons of $\mathrm{CO}_{2}$ and the overall amount is limited to 8 million tons of $\mathrm{CO}_{2}$ per year. This equals 5.6 million tonnes of $\mathrm{CO}_{2}$ avoided due to an avoidance efficiency coefficient of about $70 \%$ which is reachable in current plants. Comparing this to the energy sector related emissions of 327 million tonnes of $\mathrm{CO}_{2}$ in $2009,1.7$ per cent of these emissions could be avoided annually during the period in which the law will be valid.

In 2017, the CCS law will be reviewed; approval of large-scale CCS operations will then depend on the question if technical and environmental uncertainties will have been dispelled by 2017. Furthermore, it empowers regional governments to earmark areas where underground $\mathrm{CO}_{2}$ storage is explicitly permitted or prohibited. The new draft moreover puts emphasises on the protection of rights of land owners near storage formations. It aims at avoiding competitive usages of the underground between $\mathrm{CO}_{2}$ injection and geothermal energy production or energy storage and facilitates requests for financial compensations by municipalities located near storage sites. However, it is yet uncertain when the new CCS draft law will be officially adopted by the German parliament. Therefore, the regulatory framework for CCS in Germany is still pending so as to legal certainty for investments into CCS operations is currently not given. 


\subsection{Large-scale availability of the CCS technology}

\subsubsection{Objective and methodology}

This section is based on a screening of technical studies, presentations as well as statements of German and international CCS experts on the current state and expected course of development of the CCS in the coming years. Furthermore, the progress of ongoing or planned CCS demonstration projects in Germany was studied. The results of the screening process are summarised and used to conclude on the possible temporal availability of large-scale CCS operations.

\subsubsection{Outcomes}

As described above, the new CCS draft law explicitly limits the scale and scope of CCS activities in Germany to demonstration projects. Since the implementation of a "full" CCS law after 2017 is quite unclear, energy utilities might retard planning and financing large-scale power plants which might delay the applicability of integrated CCS systems at large scales in Germany. Usually the process of scaling-up technologies from the demonstration stage to actual commercialisation requires several years, and starting demonstration in 2015 would let expect commercialised power plants not before 2025 (Scheffknecht 2005). Besides the development of the CCS based power plant itself, a transport infrastructure and safe storage systems have to be available, which need further years for planning, testing and implementation. Altogether, in Germany the whole CCS chain might not be available in commercial dimensions before 2025 to 2030 .

This development is framed by other barriers, in particular local opposition in potential $\mathrm{CO}_{2}$ storage regions (Schleswig-Holstein and Brandenburg), which have already retarded testing and exploration activities at geological formations that are being considered for $\mathrm{CO}_{2}$ storage.

While better frame conditions in other countries could let expect a commercial operation of CCS by 2020, some experts from scientific institutions and from NGOs expect a later large-scale availability of CCS also on the international level (MIT 2007; Greenpeace 2008). Even the European Technology Platform for Zero Emission Fossil Fuel Power Plants (ZEP) expects early commercial projects operating not before 2025 in the "standard case". Since fully integrated CCS projects, including transport and storage, would take 6.5 to 10 years before they become operational, ZEP recommends enabling a "fast track" process to have CCS operational in 2020 (ZEP 2008).

\subsection{Energy scenario analysis on the available $\mathrm{CO}_{2}$ emissions for storage under an ambitious climate protection policy in Germany}

\subsubsection{Objective and methodology}

Scenario analysis is used to analyse the future role, CCS could play in the electricity sector in comparison to renewable energies in Germany. The developed scenarios are based on the Lead Scenario 2008 of the German Ministry for the Environment (BMU 2008) which aims to reduce energy related $\mathrm{CO}_{2}$ emissions by 80 per cent in 2050 , compared to 1990 level (neither using nuclear energy nor CCS). For our scenarios, it is assumed that energy management targets set by the German government and implemented in the Lead Scenario, such as a doubling of energy productivity by 2020 compared to 1990 levels; a 25 per cent share of combined heat and power 
generation (CHP) in 2020 and the required significant expansion of renewable energies (REN) (a 30 to 35 per cent share of renewable energies in electricity generation by 2020 and an approximately 50 per cent share by 2030) will indeed be implemented. However, it is assumed that the necessary efficiency measures will only be realised to a moderate extent. The varying use of CCS is envisaged for the remaining demand for electricity from fossil sources, and the overall target is to determine under which of the CCS based scenarios the climate target could be reached as well.

\subsubsection{Outcomes}

The use of CCS is depicted in a scenario family "CCS-REN/CHP", comprising six variants of the expansion of CCS capacity. A differentiation is made between new power plants and retrofitted power plants commissioned between 2010 and 2020 as well as between large-scale condensation power stations and CHP plants, which generally have less capacity. It is furthermore assumed that new fossil fuel-fired power plants built between 2005 and 2010 will be replaced by new CCS power plants at the end of their service life, i.e. between 2045 and 2050. While the upper variant "Maximal-theoretical" assumes that each new power plant will either be CCS based or retrofitted later on, the remaining scenarios foresee a lower penetration with $\mathrm{CO}_{2}$ capture (see Table 1). For example, the scenario variant "Realistic I" assumes that - due to the lack of storage sites - no power plant in South Germany is equipped with CCS and that CHP plants can only be equipped to a small extent.

Table 1: Proportion of power plants equipped with CCS in the investigated variants of scenario CCS-REN/CHP

\begin{tabular}{lcccc}
\hline Scenario variants & \multicolumn{2}{c}{ Condensating power plant } & \multicolumn{2}{c}{ Combined heat and power plant } \\
& New & Retrofitting & New & Retrofitting \\
\hline 1. Maximal - theoretical & $100 \%$ & $100 \%$ & $100 \%$ & $100 \%$ \\
2. Maximal - realistic & $100 \%$ & $65 \%$ & $75 \%$ & $35 \%$ \\
3. Maximal - new & $100 \%$ & - & $75 \%$ & - \\
4. Realistic I & $75 \%$ & $40 \%$ & $40 \%$ & $20 \%$ \\
5. Realistic I (only coal) & $75 \%$ & $40 \%$ & $40 \%$ & $20 \%$ \\
6. Realistic II & $50 \%$ & $30 \%$ & $30 \%$ & $15 \%$ \\
\hline
\end{tabular}

The results show that the potential role of CCS in the context of a German climate protection strategy largely depends on previously selected energy strategies. In the occurrence of a continued significant expansion of renewable energies and a steadily increasing share of CHP generation in the German power supply the scope for a further reduction of $\mathrm{CO}_{2}$ in the remaining fossil segment of power supply using CCS is considerably restricted.

The variant "Realistic I" results in an installed CCS capacity of 20 GW (not including penalty load) in 2050 and a $\mathrm{CO}_{2}$ reduction of 46 million tonnes compared with an equally sized electricity generation without CCS. This amount constitutes 18 per cent of the total avoidable $\mathrm{CO}_{2}$ emissions in the electricity sector between 2005 und 2050, and 8 per cent of that within the entire power supply. In this case, electricity generation from CCS power plants would make up a 12 per cent share of the total power generation in 2050 (see Figure 2) and 11 per cent share of the total 
installed power in 2050 (see Figure 3). 64 million tonnes of $\mathrm{CO}_{2}$ would have to be stored underground in 2050.

For comparison, in the case of a maximum CCS implementation strategy ("Maximum-theoretical"), 41 GW of CCS based capacity could be installed in 2050, which is 22 per cent of the totally installed load, thereby saving 85 million tonnes of $\mathrm{CO}_{2}$ and requiring 117 million tonnes of $\mathrm{CO}_{2}$ to be stored.

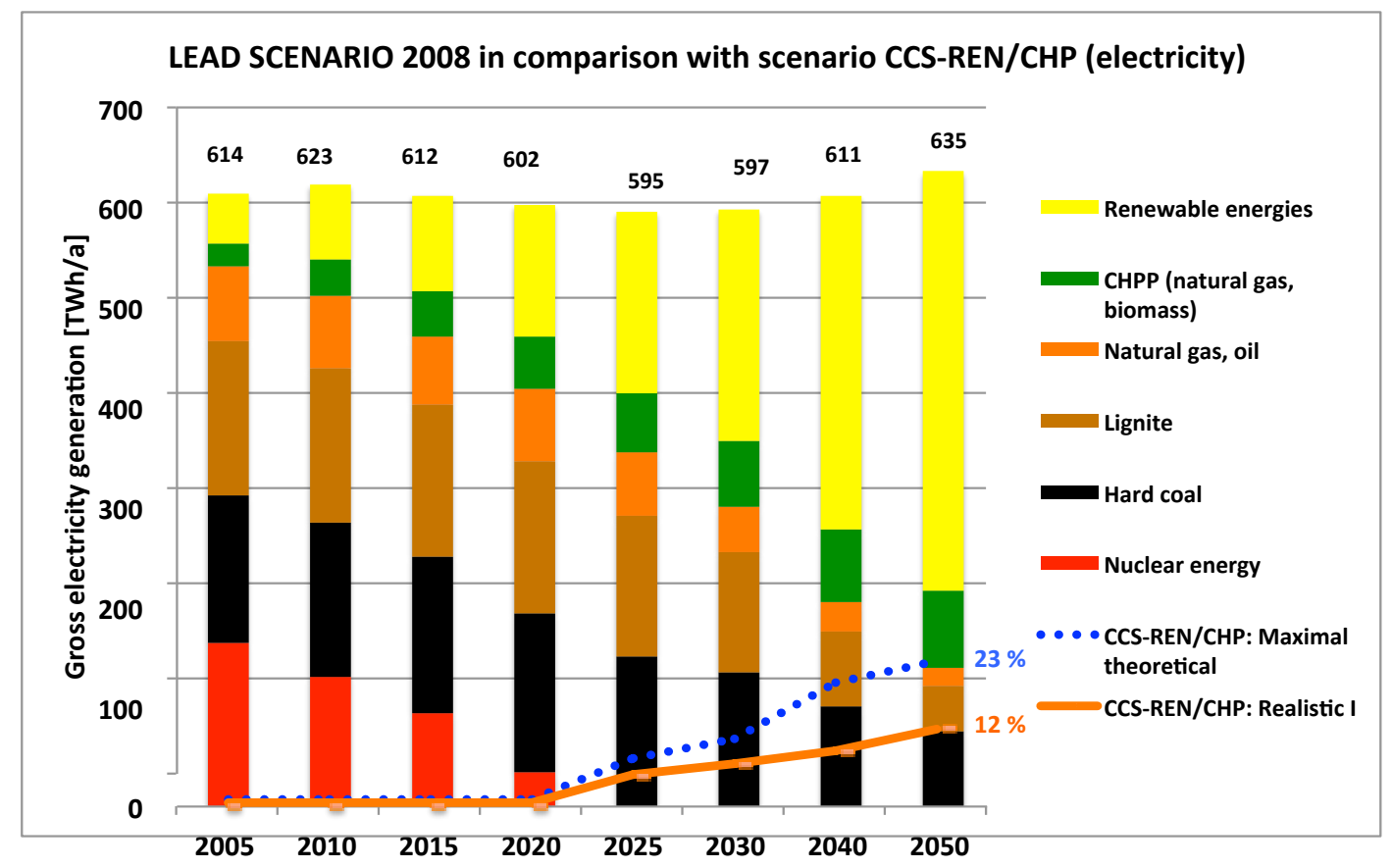

Figure 2: Overall electricity generation in the Lead Scenario 2008 and contribution of CCS in two variants of scenario CCS-REN/CHP

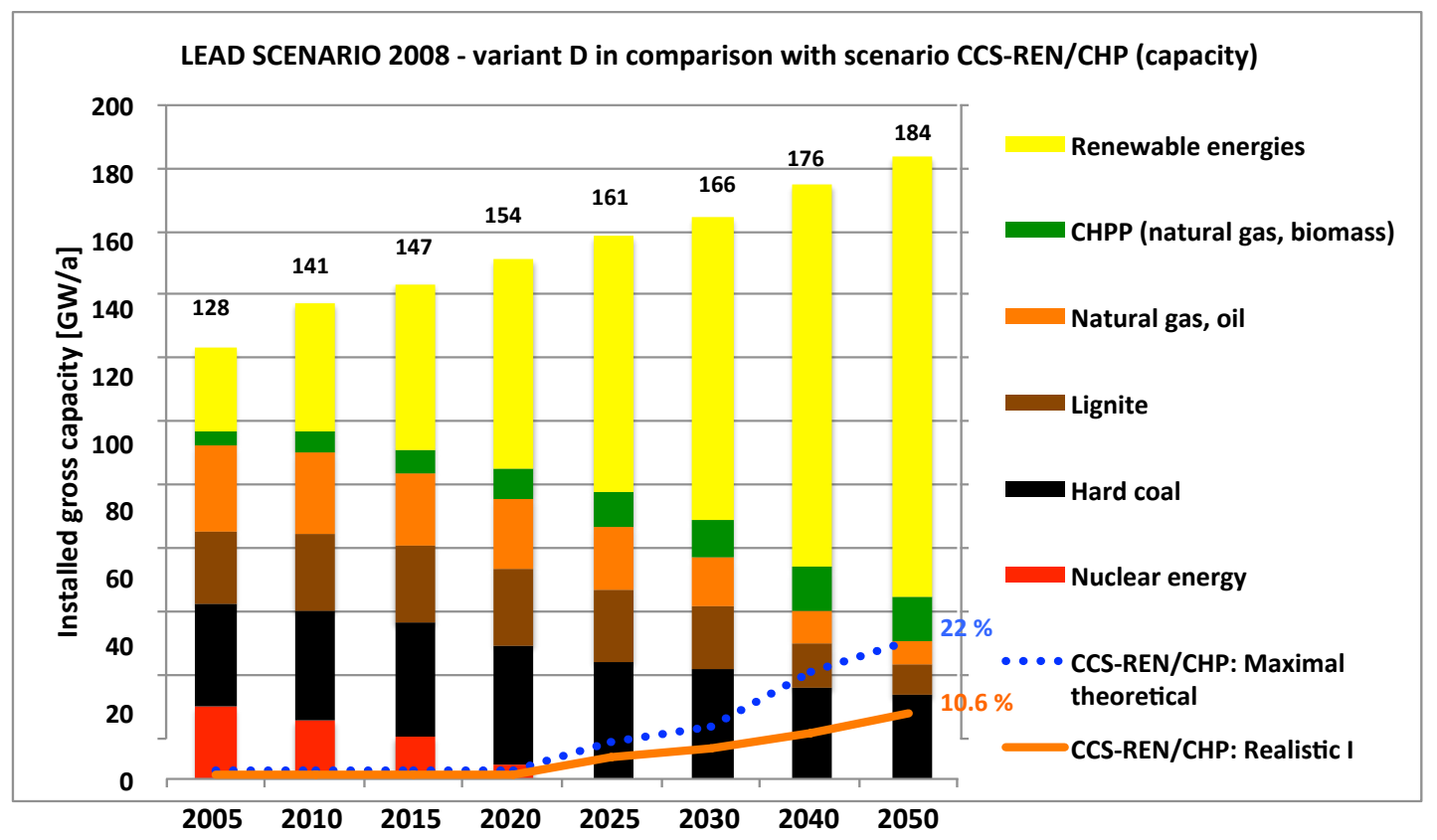

Figure 3: Development of the power plant capacity in the Lead Scenario 2008 and contribution of CCS in two variants of scenario CCS-REN/CHP (not including "penalty load" of CCS power plants) 
Figure 4 illustrates, that the scenario variant "Maximal-theoretical" would exceed the envisaged climate targets in the electricity sector (reaching 10.5 million tonnes of $\mathrm{CO}_{2}$ in 2050 instead of 28 million tonnes), while scenario "Maximal-realistic" virtually reaches the target exactly. But the variants "Realistic I" and "Realistic II" would fail the target by 78 to 125 per cent, reaching only levels of 50 and 63 million tonnes of $\mathrm{CO}_{2}$ in 2050. Applying no CCS, on the other hand, would result in 100 million tonnes of $\mathrm{CO}_{2}$ in 2050, which is caused - according to the scenario assumptions - by the insufficiently implemented energy efficiency measures.

Furthermore it becomes apparent that the $\mathrm{CO}_{2}$ reductions achieved by expanding renewable energies could be considerably larger for the same period (curve "renewables frozen"). However, it would necessitate a considerable restructuring of the power industry and infrastructure - including the need for not only completely different transmission network structures but also energy storage facilities.

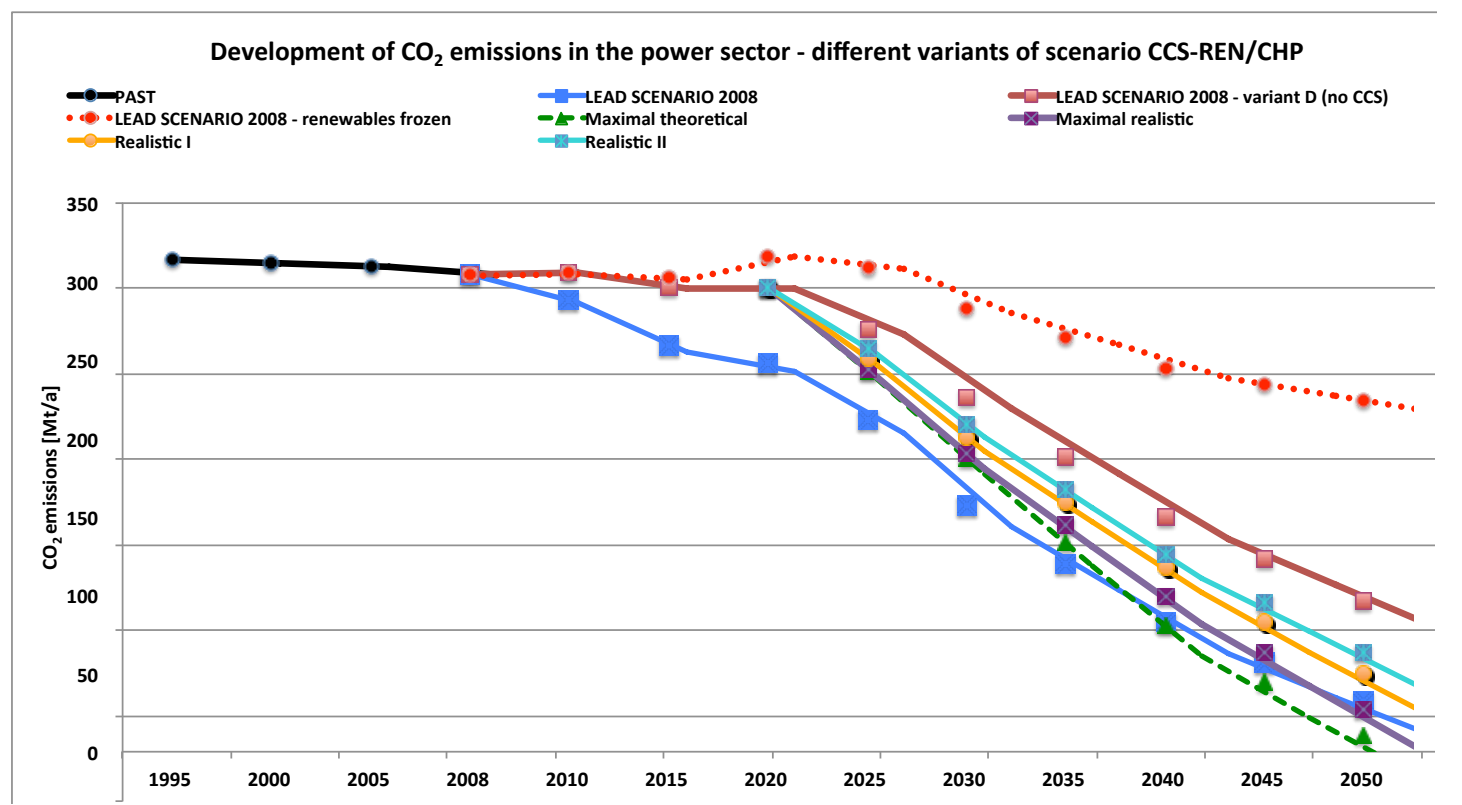

Figure 4: Course of $\mathrm{CO}_{2}$ emissions in the German electricity sector in the different variants of scenario CCS-REN/CHP compared with the original Lead Scenario 2008

\subsection{Development of power production cost: The race in learning effects between CCS backed fossil fuels and renewable energies}

\subsubsection{Objective and methodology}

In this section the levelised cost of electricity generation (LCOE) of future CCS based power plants are assessed and compared with the LCOE of renewable energies. The investment costs as well as the operating costs for CCS based power plants are taken from a literature review while those of renewable energies are cited from BMU (2008). In both cases, the learning curve approach is used to update future costs, while the LCOE are calculated using the annuity method. In case of renewable energies, a sustained global increase in market penetration with respecting learning effects is assumed. It should be noted that no excess capacities are included in this calculation. 
Since energy price trajectories are the most influential factor in calculating the LCOE, three different variants ("considerable", "moderate" and "very low") are considered (taken from BMU 2008). Similarly, three trajectories for $\mathrm{CO}_{2}$ allowances are included.

The utilisation period of fossil fired power plants is taken from the energy scenario analysis (section 2.5.). The figures show constantly decreasing full load hours for fossil fired power plants (getting down from 5,616 h/y in 2010 to 3,589 h/y in 2050) which result from the massive deployment of renewable energy plants. Table 2 illustrates the main figures assumed for the power plants while

Table 3 shows the underlying assumptions on energy prices and full load hours.

Table 2: Expenses, costs and other parameters of "market-ready" CCS power plants (2020), "mature" CCS power plants (2040) and their reference power plants (2020)

\begin{tabular}{|c|c|c|c|c|c|c|c|c|c|}
\hline & & \multicolumn{2}{|c|}{$\begin{array}{l}\text { Natural gas } \\
\text { NGCC }\end{array}$} & \multicolumn{2}{|c|}{$\begin{array}{l}\text { Hard coal } \\
\text { Steam }\end{array}$} & \multicolumn{2}{|c|}{$\begin{array}{l}\text { Hard coal } \\
\text { IGCC }\end{array}$} & \multicolumn{2}{|c|}{$\begin{array}{l}\text { Lignite } \\
\text { Steam }\end{array}$} \\
\hline & & 2020 & 2040 & 2020 & 2040 & 2020 & 2040 & 2020 & 2040 \\
\hline \multicolumn{10}{|l|}{ A) Without $\mathrm{CO}_{2}$ capture } \\
\hline Degree of utilisation & $\%$ & 60.0 & 62.0 & 49.0 & 52.0 & 50.0 & 54.0 & 46.0 & 49 \\
\hline Investment & $€ / \mathrm{kW}_{\mathrm{el}}$ & 400 & 400 & 950 & 900 & 1,300 & 1,100 & 1,100 & 1,050 \\
\hline Operation, maintenance & $€ / \mathrm{kW}_{\mathrm{el}, \mathrm{a}}$ & 34.1 & 32 & 48.3 & 45 & 53 & 49 & 56 & 52.5 \\
\hline $\mathrm{CO}_{2}$ emissions, direct & $\mathrm{g} / \mathrm{kWh}_{\mathrm{el}}$ & 337 & 326 & 690 & 650 & 676 & 626 & 880 & 827 \\
\hline \multicolumn{10}{|l|}{ B) With $\mathrm{CO}_{2}$ capture } \\
\hline Degree of utilisation & $\%$ & 51.0 & 55.0 & 40.0 & 44.0 & 42.0 & 46.0 & 34 & 39 \\
\hline $\begin{array}{l}\text { Reduction of degree of } \\
\text { utilisation }\end{array}$ & $\begin{array}{l}\% \\
\text { points }\end{array}$ & 9 & 7 & 9 & 8 & 8 & 8 & 12 & 10 \\
\hline Investment & $€ / \mathrm{kW}_{\mathrm{el}}$ & 900 & 750 & 1,750 & 1,600 & 2,000 & 1,700 & 2,030 & 1,870 \\
\hline Difference in investment & $€ / k W_{e l}$ & 500 & 350 & 800 & 700 & 700 & 600 & 930 & 820 \\
\hline Operation, maintenance & $€ / \mathrm{kW}_{\mathrm{el}}, \mathrm{a}$ & 54 & 50 & 80 & 74 & 85 & 78 & 94 & 86 \\
\hline $\begin{array}{l}\text { Difference in operation, } \\
\text { maintenance }\end{array}$ & $€ / k W_{e l,} a$ & 20.1 & 18 & 31.7 & 29 & 32 & 29 & 38 & 33.5 \\
\hline $\begin{array}{l}\text { Compression, } \\
\text { transport and storage }\end{array}$ & $\mathrm{ct} / \mathrm{kWh}_{\mathrm{el}}$ & 0.20 & 0.18 & 0.40 & 0.36 & 0.40 & 0.36 & 0.40 & 0.36 \\
\hline Capture rate & $\%$ & 88 & 92 & 88 & 90 & 88 & 92 & 88 & 90 \\
\hline Additional use of fuel & $\%$ & 18 & 13 & 23 & 18 & 19 & 17 & 35 & 26 \\
\hline $\mathrm{CO}_{2}$ emissions, direct & $\mathrm{g} / \mathrm{kWh}_{\mathrm{el}}$ & 48 & 29 & 101 & 77 & 97 & 59 & 143 & 104 \\
\hline $\mathrm{CO}_{2}$ emissions, avoided & $\mathrm{g} / \mathrm{kWh}_{\mathrm{el}}$ & 289 & 297 & 589 & 573 & 579 & 567 & 737 & 723 \\
\hline
\end{tabular}


Table 3: $\mathrm{CO}_{2}$ penalties, energy prices and full load hours used as basis for the economic calculation

\begin{tabular}{|c|c|c|c|c|c|c|c|c|c|}
\hline & Unit & 2005 & 2010 & 2015 & 2020 & 2025 & 2030 & 2040 & 2050 \\
\hline \multicolumn{10}{|l|}{$\mathrm{CO}_{2}$ penalty } \\
\hline Price trajectory $A$ & $€ / t$ & & 24 & 32 & 39 & 45 & 50 & 55 & 60 \\
\hline Price trajectory B & $€ / t$ & & 20 & 25 & 30 & 33 & 35 & 37.5 & 40 \\
\hline Price trajectory $\mathrm{C}$ & $€ / t$ & & 15 & 18 & 20 & 21.5 & 23 & 24.5 & 26 \\
\hline \multicolumn{10}{|l|}{$\begin{array}{l}\text { Natural gas } \\
\text { price }\end{array}$} \\
\hline Price trajectory A & $€_{2005} / G J_{\text {th }}$ & 4.66 & 7.83 & 9.17 & 10.67 & 12.2 & 13.79 & 15.16 & 16.53 \\
\hline Price trajectory B & $€_{2005} / G J_{\text {th }}$ & 4.66 & 6.92 & 7.65 & 8.43 & 9.22 & 9.99 & 10.63 & 11.26 \\
\hline Price trajectory $\mathrm{C}$ & $€_{2005} / G J_{\text {th }}$ & 4.66 & 6.26 & 6.53 & 6.81 & 7.17 & 7.51 & 7.80 & 8.09 \\
\hline \multicolumn{10}{|l|}{ Hard coal price } \\
\hline Price trajectory A & $€_{2005} / G J_{\text {th }}$ & 2.1 & 3.91 & 4.59 & 5.33 & 6.1 & 6.89 & 7.72 & 8.54 \\
\hline Price trajectory B & $€_{2005} / G J_{\text {th }}$ & 2.1 & 3.46 & 3.82 & 4.22 & 4.61 & 5,00 & 5.32 & 5.63 \\
\hline Price trajectory $\mathrm{C}$ & $€_{2005} / \mathrm{GJ}_{\text {th }}$ & 2.1 & 3.03 & 3.17 & 3.30 & 3.48 & 3.65 & 3.80 & 3.95 \\
\hline \multicolumn{10}{|l|}{$\begin{array}{l}\text { Lignite } \\
\text { (domestic) price }\end{array}$} \\
\hline Price trajectory A & $€_{2005} / G J_{\text {th }}$ & 1.05 & 1.12 & 1.2 & 1.25 & 1.3 & 1.37 & 1.44 & 1.50 \\
\hline Price trajectory B & $€_{2005} / G J_{\text {th }}$ & 1.05 & 1.12 & 1.17 & 1.22 & 1.27 & 1.32 & 1.37 & 1.41 \\
\hline Price trajectory $\mathrm{C}$ & $€_{2005} / G J_{\text {th }}$ & 1.05 & 1.11 & 1.14 & 1.17 & 1.22 & 1.25 & 1.29 & 1.33 \\
\hline \multicolumn{10}{|l|}{ Full load hours } \\
\hline Utilisation period & $\mathrm{h} / \mathrm{y}$ & & 5,616 & 5,137 & 4,936 & 4,861 & 4,579 & 3,951 & 3,589 \\
\hline $\mathrm{A}=$ considerable & $=$ moderat & ver & & & & & & & \\
\hline
\end{tabular}

\subsubsection{Outcomes}

\subsubsection{Levelised electricity generation cost of CCS based power plants}

After successfully demonstrating the entire CCS chain (capture, transport and, in particular, storage of $\mathrm{CO}_{2}$ ), according to our calculations, electricity generating costs from CCS power plants of between 7.30 and $10.35 \mathrm{ct} / \mathrm{kWh}_{\mathrm{el}}$ (at power plant) can be achieved by 2020 (assumed real interest rate 6 per cent per annum). The price range depends on both the technology taken into consideration and the price trends of fuel and $\mathrm{CO}_{2}$ allowances up to 2020 . The usage fees for storage sites ("storage fee"), as called for by several federal states and the German Advisory Council on the Environment, have not yet been included.

Two scenarios were considered: "scenario C/A" considers very low increasing fuel costs (price trajectory $\mathrm{C}$ ) with high $\mathrm{CO}_{2}$ penalties (price trajectory A) while "scenario 
A/C" considers considerably rising energy costs (price trajectory A) that cause a surplus of and, therefore, decreasing $\mathrm{CO}_{2}$ penalties (price trajectory $\mathrm{C}$ ). In the latter case, which we consider to be the more realistic scenario, $\mathrm{CO}_{2}$ avoidance costs in 2020 of $68 € / \mathrm{t} \mathrm{CO}_{2}$ (natural gas), $43 € / \mathrm{t} \mathrm{CO}_{2}$ (hard coal) and $20 € / \mathrm{CO}_{2}$ (lignite) are produced (see Figure 5).

Depending on further price trends, the long-term cost projections of CCS range from 8.10 to $13.80 \mathrm{ct} / \mathrm{kWh}_{\mathrm{el}}$ in 2040 and from 8.80 to $15.40 \mathrm{ct} / \mathrm{kWh}_{\mathrm{el}}$ in 2050 . Lignite steam power plants are in the lower region, hard coal power plants (steam and gasification) are in the medium to high range, and natural gas in the top range. Despite increasing running costs, $\mathrm{CO}_{2}$ avoidance costs decrease due to learning effects by 2040 to $61 € / \mathrm{t} \mathrm{CO}_{2}$ (natural gas), $36 € / \mathrm{t} \mathrm{CO}$ (hard coal) and $17 € / \mathrm{t} \mathrm{CO}_{2}$ (lignite).

\subsubsection{Comparison with electricity generation cost from renewable energies}

The average electricity generating costs of renewable energies are presently around $12 \mathrm{ct} / \mathrm{kWh}_{\mathrm{el}}$, assuming a representative mix of renewable energy sources (also calculated at a real interest rate of 6 per cent per annum). When photovoltaics are excluded from the mix, the average costs amount to around $10 \mathrm{ct} / \mathrm{kWh}_{\mathrm{el}}$. If they continue to be deployed at a similar speed as before, levelised electricity generating costs of approximately $8.8 \mathrm{ct} / \mathrm{kWh}_{\mathrm{el}}$ (including photovoltaics) and $8.2 \mathrm{ct} / \mathrm{kWh}_{\mathrm{el}}$ (excluding photovoltaics) might be achieved by 2020. A sustained global increase in market penetration and learning effects give reasons to expect further significant cost degression for renewable energies over time. By 2050, therefore, the level of costs in the investigated characteristic mix could be around $8.8 \mathrm{ct} / \mathrm{kWh}_{\mathrm{el}}$. Technologies such as offshore wind power or geothermal energy could achieve electricity costs of around $5 \mathrm{ct} / \mathrm{kWh}_{\mathrm{el}}$ if their learning curve continues to be used for the further expansion of global markets (see Figure 5). 


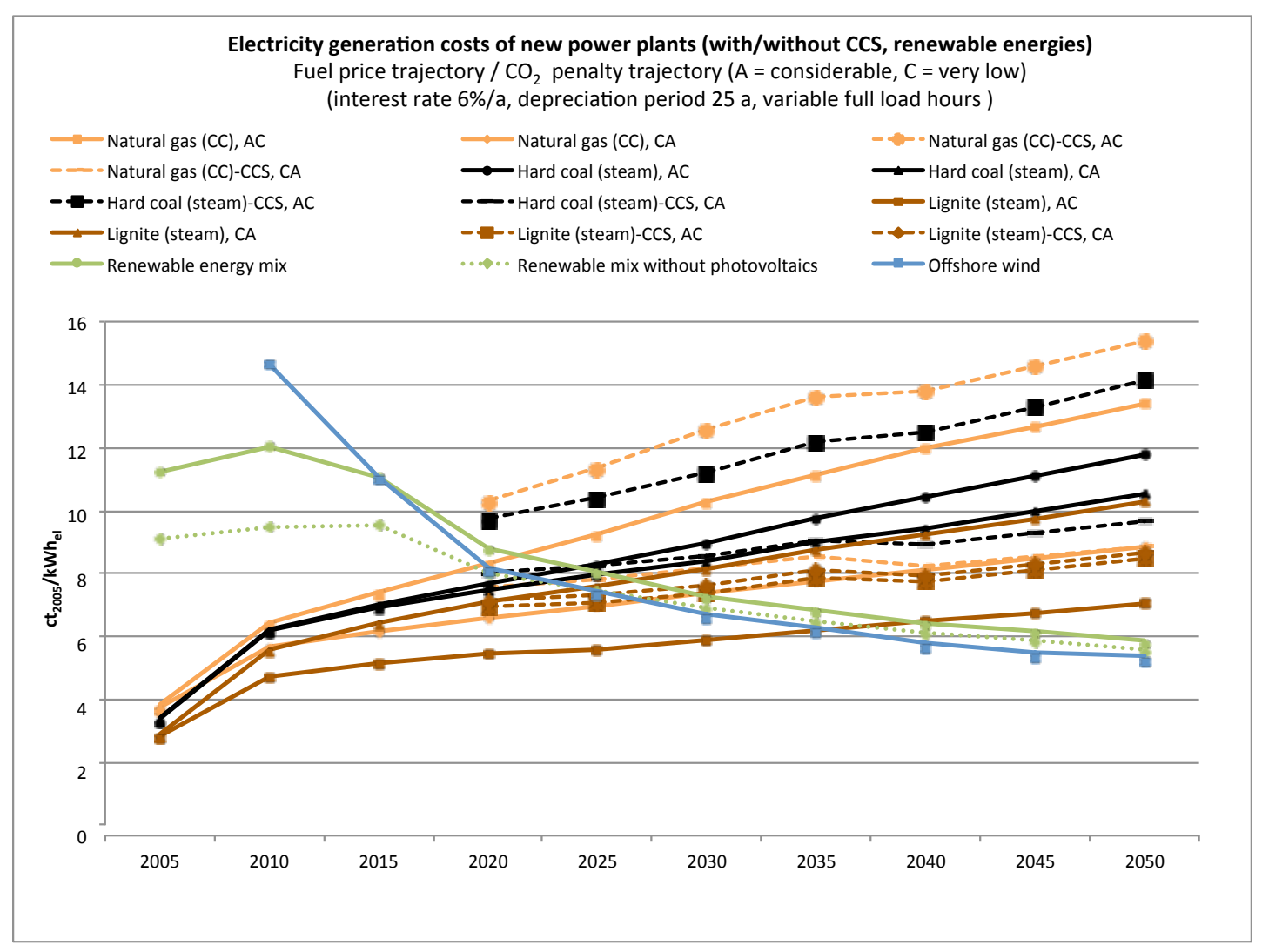

Figure 5: Development of future electricity generating costs (new plants) for renewable energies and fossil fuel-fired power plants (with/without CCS) for fuel price trajectories $/ \mathrm{CO}_{2}$ penalty trajectories $\mathrm{A} / \mathrm{C}$ and $\mathrm{C} / \mathrm{A}$ (CCS from 2020, including transport and storage)

If the dynamics of the expansion of renewable energies in the electricity sector remains high, as assumed in the scenario family "CCS-REN/CHP" (section 2.5), individual renewable energy technologies (offshore and onshore wind power, solar thermal power plants) will be able to compete with CCS power plants as early as in 2020 , which is considered to be the potential starting point for CCS power plants. The average mix is partially competitive even now. If fuel prices increase considerably, the generating costs of CCS-based natural gas- and hard coal-fired power plants will be higher from 2020 than for renewable energies. Lignite-fired CCS power plants will follow from 2025 (offshore wind/solar thermal energy) and 2030 (mix of renewable energies). Even in the case of very small increases in energy prices, the additional costs incurred by CCS would be so high that renewable energies would remain competitive at the same time as in the high price scenario. The high $\mathrm{CO}_{2}$ penalty, which cannot be fully compensated by $\mathrm{CO}_{2}$ capture, has a particularly powerful impact on lignite.

\subsection{Assessment of environmental impacts of CCS and renewable energies based electricity generation in an LCA perspective}

\subsubsection{Objective and methodology}

The aim of this part is to review existing life cycle assessment (LCA) studies on CCS and to compare the environmental impacts with those resulting from selected 
renewable energy plants. Only such studies are reviewed in which an LCA according to the relevant standards (ISO 14.040ff) was carried out and which considered several environmental impact categories. Besides an LCA from the former RECCS study (WI et al. 2007), four studies published in 2008 and 2009 were selected (Bauer et al. 2008, Koornneef et al. 2008, Schreiber et al. 2009, Pehnt and Henkel 2009). They cover both hard coal and lignite fired steam power plants and look at different capture technologies. While most studies compare current fossil fired power plants with CCS based power plants anticipating efficiency levels for 2020, the most extensive study (NEEDS) pictures possible future situations in 2025 as well as in 2050 (Bauer et al. 2008).

\subsubsection{Outcomes}

\subsubsection{Environmental impacts of CCS based electricity generation}

The findings of (WI et al. 2007) for post-combustion processes were mainly confirmed, even if in the latest studies (in particular, by Koornneef et al. 2008) the capture and, in part, transport and storage were modelled in more detail. Substantial new findings were generated for pre-combustion and oxyfuel, despite the fact that the capture processes have not yet been considered in detail. The only value given in all of the studies is that of greenhouse gas emissions, consisting mainly of $\mathrm{CO}_{2}, \mathrm{CH}_{4}$ and $\mathrm{N}_{2} \mathrm{O}$ emissions. They are particularly relevant in the case of hard coal- and natural gas-fired power plants because considerable methane emissions $\left(\mathrm{CH}_{4}\right)$ are created here in the upstream chains. This effect is intensified by the increased energy consumption of CCS power plants. The capture rates and initial emissions in 2020 are generally assumed to be identical in all studies. Considerable deviations are visible, however, in the reduction of greenhouse gas emissions. The reason for this is that varying assumptions are made on the additional energy consumption caused by capture, and hence the reduction in the degrees of utilisation. In the NEEDS study (Bauer et al. 2008), in particular, significantly lower losses than in other studies are assumed.

Table 4 illustrates the rates of reduction of greenhouse gases which are given for 2020/2025, based on capture rates of $88-92$ per cent (in case of oxyfuel $92-99.5$ per cent):

Table 4: Overall rates of reduction of greenhouse gases, resulting from different capture processes in 2020/2025

\begin{tabular}{lcccc}
\hline Primary Energy & Units & \multicolumn{2}{c}{ Steam power plant } & IGCC \\
\hline Capture process & & Post combustion & Oxyfuel combustion & Pre combustion \\
\hline Hard coal & $\%$ & $67-72$ & $78-85$ & $67-68$ \\
Lignite & $\%$ & $78-81$ & $87-95$ & $83-84$ \\
Natural gas & $\%$ & $67-75$ & & \\
\hline
\end{tabular}

However, other environmental impacts should be considered in addition to greenhouse gas emissions. The higher energy consumption required in all of the processes and the materials used in the capture processes can be perceived in direct proportion to the various impact categories of the LCA. Depending on the assumptions made in the studies, the various interactions in the capture processes lead to many trade-offs in the individual environmental impact categories. In some 
studies, all emissions increase in accordance with the additional energy consumption (for example the potentials of eutrophication, abiotic depletion, photochemical oxidation the human toxicity), other studies, however, model trade-offs that arise from the simultaneous reduction of other emissions in the course of the $\mathrm{CO}_{2}$ capture process (for example the acidification potential). A considerable decrease in all environmental impacts can generally be assumed with oxyfuel capture (see Viebahn 2011 for a detailed analysis).

\subsubsection{Comparison with electricity generation from renewable energy sources}

For the comparison with renewable energies, only greenhouse gas emissions are taken into account since they are the only emissions reported in all CCS studies. We use the results from the aforementioned NEEDS study, in which also a number of renewable energies were investigated in terms of their future development. The minimum and maximum values from three technology scenarios ("pessimistic", "optimistic-realistic" and "very optimistic") are selected. Offshore wind power (DONG Energy 2008), photovoltaics (Frankl et al. 2008) and solar thermal power plants (Viebahn et al. 2011) are used for the comparison with CCS power plants. It should be noted that the LCA for solar thermal power plants considers both the balance of a power plant in north Africa (Algeria) and the high voltage transmission line to Germany including the arising transmission losses.

In case of CCS based power plants, the minimum and maximum values and the mean of all options, considered in the former section, are given. The range results from combining steam power plants and IGCC.

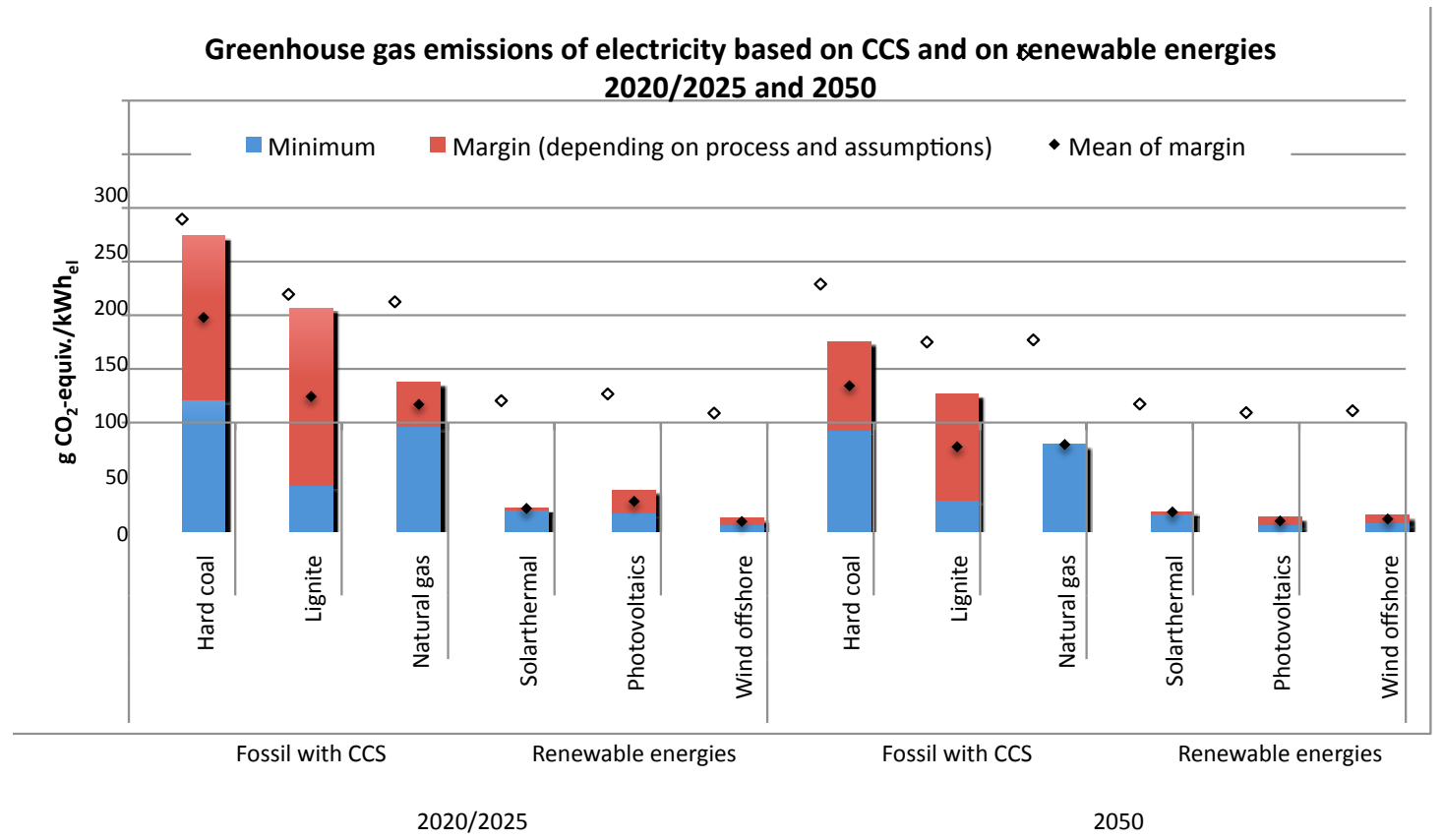

Figure 6: Greenhouse gas emissions from fossil fuel-fired power plants with CCS in comparison with electricity from emissions from renewable based power plants (solar thermal power plants, photovoltaics and offshore wind, both for 2020/2025 and 2050)

Figure 6 shows that renewable energies, even compared to CCS power plants, create only a fraction of greenhouse gas emissions (most of which originate from the 
construction of the plant). The chart illustrates that in 2025, offshore wind could create only 5 to 8 per cent, solar thermal energy 11 to 18 per cent and photovoltaics 14 to 24 per cent of the emissions of CCS power plants. By 2050, photovoltaics could improve, in particular, releasing only 7 to 12 per cent of the emissions of CCS power plants; offshore wind creates 9 to 15 per cent and solar thermal energy 13 to 23 per cent.

\subsection{Available storage capacity in Germany}

\subsubsection{Objective and methodology}

The most crucial step within the whole CCS process chain is the underground storage of $\mathrm{CO}_{2}$. Since the political discussion rarely considers the potentially available storage capacities, in the first step existing capacity estimates for Germany are systematically analysed and compared with regard to their methods and assumptions. Since basic parameters used in the reviewed studies were either not published or not backed up adequately, secondly, an own cautious, conservative estimate for the effective capacity is presented. The intention is to provide a lower limit for the storage space for orientation purposes for potential investors and political decisionmakers. In this sense the own estimate can be seen as a sensitivity analysis complementing the reviewed studies in which the most crucial parameter, the efficiency factor, is varied.

\subsubsection{Outcomes}

\subsubsection{Results of the meta analysis}

When calculating storage potentials, a methodological distinction is made between a "top-down" and a "bottom-up" approach. In the "top-down" approach, a total volume (for example, for the whole of Germany) is assumed. This total volume is then restricted according to various criteria like sufficient porosity, density of $\mathrm{CO}_{2}$, share of closed structures etc. ("volumetric concept"). The resulting "theoretical potential" is further shrunk reduced to the "effective potential" by applying an "efficiency factor" which takes the potential water displacement and compressibility into account. Using the "bottom-up" method, single structures are considered and their capacities added together to calculate the total storage potential. While the volumetric concept is usually used for aquifers, the "bottom-up" approach is generally applied for hydrocarbon fields.

It is evident that a general top-down approach can only provide unsecure results and a site-specific analysis for all potential storage sites is needed in order to decrease the uncertainty range. That's why some new aquifer assessments rely also on the bottomup approach but do not provide results for the entire country so far. Therefore, in the following, an overview only on existing studies which consider saline aquifers (onshore and offshore) and hydrocarbon fields for Germany in total, are given (see WI 2010 for a detailed analysis).

Table 5: $\mathrm{CO}_{2}$ storage capacities for Germany in various formations

\begin{tabular}{lcccc}
\hline & JOULE II & GESTCO & BGR & GeoCapacity \\
Formation & 1996 & 2004 & 2005 & 2009 \\
\hline
\end{tabular}




\begin{tabular}{lcccc} 
Onshore saline aquifers & 0.47 & $23-42$ & $12-28$ & 12 \\
North Sea aquifers & $?$ & $?$ & $4-10$ & 2.9 \\
Gas fields & 2.34 & 2.23 & 2.75 & 2.81 \\
Oil fields & 0.06 & 0.10 & 0.11 & marginal \\
\hline Total & $\approx 3$ & $25-44$ & $19-41$ & $\approx 18$ \\
\hline All values given in Gt CO 2 & & & \\
The values for gas fields contain reserves. \\
JOULE II: van der Straaten et al. (1996); GESTCO: Christensen and Holloway (2004); \\
BGR: May et al. (2005); May (2009); Gerling (2008); GeoCapacity [conservative]: \\
Vangkilde-Pedersen et al. (2009)
\end{tabular}

The analysed four publications for Germany (see Table 5) deliver a range of storage capacity from 3 to $44 \mathrm{Gt} \mathrm{CO}_{2}$ which shows the very high uncertainty. The biggest difference is referred to saline aquifers which are calculated top-down. A large range is provided by onshore aquifers ( 0.5 to $42 \mathrm{Gt}$ ) where the efficiency factor is the most significant parameter. This factor ranges from 2 to 40 per cent, that means a variation of a factor of 20. The different values for the efficient factors depend on whether closed or open systems are considered and to which volume the estimate refers. The density of the $\mathrm{CO}_{2}$ varies between 600 and $700 \mathrm{~kg} / \mathrm{m}^{3}$ which causes smaller deviations between 14 and 17 per cent. Offshore basins are not even analysed in the lowest (JOULE II) and highest (GESTCO) estimates.

The results for gas fields are very similar and are based on reserve data and the assumption that 100 per cent of the extracted gas can be replaced by $\mathrm{CO}_{2}$. The storage capacity in oil fields is rather irrelevant as it is very low.

\subsubsection{Cautious storage capacity estimate for Germany}

As seen above, the high level of variation between the estimates is mainly based on the efficiency factor. In the studies summarised in Table 5 this factor is arbitrarily chosen and is applied on either the trap volume of an aquifer or the total pore volume. For gas fields, no efficiency factor at all is integrated. In this section, the storage capacity of Germany is assessed based on more comprehensible assumptions regarding the efficiency factor to provide a lower limit for the storage capacity.

- For aquifers, we take mainly into account that the underground pore space of aquifers is saturated with saline water. Thus the available pore space is only usable to a small extent for $\mathrm{CO}_{2}$ storage if displacement of this strong saline water is to be avoided. If no formation water is produced out of the aquifer, the efficiency is controlled by the maximum pressure increase in the system.

- In the case of gas fields, new studies argue that it is rather unlikely that the entire volume of extracted gas is available for $\mathrm{CO}_{2}$ storage, that means a sweep efficiency lower than 100 per cent should be included. (Holloway et al. 2006, IEAGHG 2009a)

\section{Aquifers (onshore)}

For aquifers, a comprehensive method of Dutch scientists (van der Meer and Yavuz 2009) is applied to achieve a cautious assessment for Germany. It is assumed that $\mathrm{CO}_{2}$ can only be injected into trap structures. Many authors justify this limitation because of its higher permanence in the formation, leading to greater public acceptance. In order to minimise the risk of potential seepage of saline water into drinking water or other environments due to injection of $\mathrm{CO}_{2}$ underground, every 
geological system is viewed as being closed so that the prevailing formation water and the injected $\mathrm{CO}_{2}$ stay in this very system. Taking into account a corresponding lower total pressure increase in the system $(1 \mathrm{MPa})$ to prevent fracturing and a low compressibility of pores and water $\left(1 * 10^{-3} / \mathrm{MPa}\right)$, an efficiency factor of 0.1 per cent is achieved by multiplication of these parameters, related to the total onshore aquifer volume. These assumptions are confirmed by recent studies, which take the lower efficiency factors into account and advocate taking only closed underground systems into consideration (Ehlig-Economides and Economides 2010, IEAGHG 2009b). Based on these assumptions, the conservative estimate of the storage capacity for Germany in onshore saline aquifers amounts to 0.84 billion tonnes of $\mathrm{CO}_{2}$. A sensitivity analyses with efficiency factors 0.045 per cent (lower compressibility of $0.45^{*} 10^{-3} / \mathrm{MPa}$ ) and 1 per cent (higher pressure increase of $10 \mathrm{MPa}$ ) yield a range of fluctuation from 0.38 to 8.4 billion tonnes of $\mathrm{CO}_{2}$.

\section{Aquifers (offshore)}

The offshore aquifers had already been estimated conservatively in the GeoCapacity report with a bottom-up approach (Vangkilde-Pedersen et al. 2009). This calculation is taken here as it seems comprehensible. It gives an average capacity of 2.9 billion tonnes of $\mathrm{CO}_{2}$ (fluctuation of 1.88 to 4.5 billion tonnes of $\mathrm{CO}_{2}$ ). These values are considerably higher than the assumed capacities for onshore aquifers, even though German onshore aquifers are larger than their offshore counterparts. This is due to the application of much higher efficiency factors than assumed for onshore aquifers because the water displacement issue has not been covered. This might be justified as saline water intrusion into the ocean water appears less harmful than contamination of potable water sources onshore.

Additionally, due to a lack of reliable data for offshore aquifers, it is impossible to carry out a comparable cautious estimate, as had been the case for onshore aquifers. But if the cautious assumptions for onshore aquifers are moderated and higher increase in pressure is permitted (upper sensitivity analysis), a different relationship between onshore and offshore appears ( $8.4 \mathrm{Gt}$ onshore towards $4.5 \mathrm{Gt}$ offshore).

\section{Hydrocarbon fields}

In contrast to the existing studies which are consistent to each other, a lower storage potential in depleted natural gas fields is achieved by including a sweep efficiency of 75 to 90 per cent. This leads to a total capacity of 1.62 to 1.94 billion tonnes of $\mathrm{CO}_{2}$, including natural gas reserves. This assumption seems to be justified because it is highly unlikely that the pores, previously filled with natural gas, would be completely filled with $\mathrm{CO}_{2}$ (IEAGHG 2009a).

\subsubsection{The total $\mathrm{CO}_{2}$ storage capacity}

Our cautious, conservative estimate for sites in Germany totals 5 billion tonnes of $\mathrm{CO}_{2}$ as the basic value. The uncertainty fluctuation yields values from 4 to 15 billion tonnes of $\mathrm{CO}_{2}$. If all reviewed studies are compared, a wide range of values, ranging from 3 to 44 billion tonnes, is produced in which our estimation lies in the lower interval of the total range (see Figure 7). 


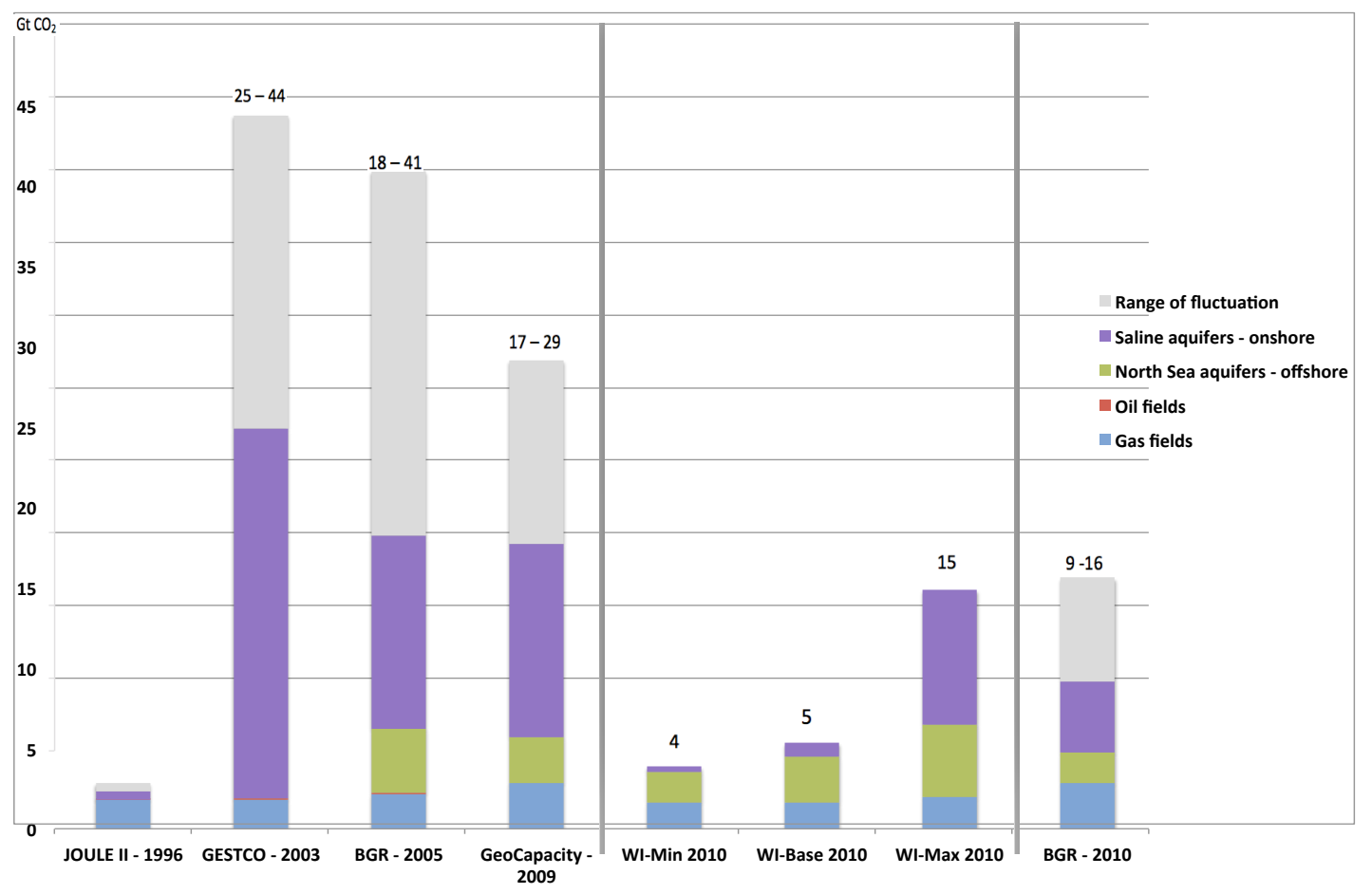

Figure 7: Estimates of $\mathrm{CO}_{2}$ storage capacities for Germany, reviewed studies and own estimation

This own estimate seems to be justified as a study of the German Geological Survey for onshore saline aquifers shows (Knopf et al. 2010), which was published shortly after providing the results of our analysis. The study analyses the most promising basins in Germany with a bottom-up approach. The selected onshore aquifers deliver a capacity of $6.4 \mathrm{Gt} \mathrm{CO}_{2}$ (range of 4.4 to $8.3 \mathrm{Gt}$ ). The results for offshore aquifers and gas fields are taken from the GeoCapacity study (1.9-4-5 Gt and 2.81 Gt, respectively). In total, a capacity of 9.1 to $15.6 \mathrm{Gt} \mathrm{CO}_{2}$ is assumed (see Figure 7) which is comparable to our maximum case.

\section{Overall results and discussion}

\subsection{Overall results of the assessment of CCS as applied in the German power plant sector}

The previous sections show that the commercialisation of CCS is affected by a broad variety of "hard" and "soft" aspects which can not be considered independently from each other. Applying the integrated assessment approach by integrating different perspectives makes it possible to draw an overall picture on both the current and the possible future situation of CCS in Germany. Evaluating the seven assessment dimensions leads to the overall conclusion that the framework conditions for CCS in the German power sector might be not favourable:

- Public opposition against $\mathrm{CO}_{2}$ storage and transportation projects has grown to a serious barrier for the large-scale introduction of CCS in Germany. Compared to the early years of the German CCS debate, the range of stakeholders has been extended to political and social stakeholders from the storage regions, both at the local and the state level. Hence, a two-level conflict is emerging: At the first level, between federal states with a great $\mathrm{CO}_{2}$ storage potential and the German government and, at the 
second level, between the "storage states" and all other federal states, especially those with a high concentration of large-point $\mathrm{CO}_{2}$ sources, such as North Rhine Westphalia.

- Translating the European CCS Directive into national legislation has turned out to be a highly controversial and complex task mainly due to concerns in the storage regions. The draft law presented by the German government recently is noticeable inspired by public opposition against $\mathrm{CO}_{2}$ storage and limits $\mathrm{CCS}$ projects to a demonstration scale until 2017. Therefore, the process of CCS development and upscaling might slowed down in Germany. However, a "fast track" process is needed to achieve an early large-scale availability of the whole CCS chain, which seems to be necessary if the use of CCS should not loose the potential role ascribed to it as a bridging technology towards a renewable power system. This also applies if other countries indicate more favourable conditions for CCS than Germany.

But even if public acceptance was given, all legislative barriers were eliminated and the whole CCS chain would be commercially available in 2020, there is likely to be only a limited demand for CCS power plants in Germany, even in the case of ambitious climate protection targets:

- If renewable energies and combined heat and power are expanded further and energy productivity is enhanced in line with the targets of the current federal government, there might be little room for a substantial use of CCS technology. According to the presented long-term scenario analysis, the - in our view - most realistic scenario "Realistic I" would enable an installed CCS capacity of 20 gigawatts in 2050, avoiding 46 million tonnes of $\mathrm{CO}_{2}$ with a total of 1.2 billion tonnes of $\mathrm{CO}_{2}$ by 2050 . This amount constitutes 18 per cent of the total avoidable $\mathrm{CO}_{2}$ emissions in the electricity sector between 2005 and 2050, and 8 per cent of that within the entire power supply system. Nevertheless, this scenario would miss the 2050 target of the electricity sector by 78 per cent, reaching only levels of 50 millions of $\mathrm{CO}_{2}$ instead of the envisaged 28 million tonnes. On the other hand, the "Maximum-theoretical" scenario would exceed the provided target, but due to the other constraints resulting from our assessment implementing such a maximum strategy would become quite improbable. Consequently, there might only be a "suboptimal" contribution left for potential CCS power plants if it is assumed that considerable financial resources will be required for further research, development and demonstration before CCS is commercially available. If, moreover, the earliest opportunity for deployment remains between 2020 and 2030, it is essential to enable the new fossil fuel-fired power plants to be retrofitted as far as possible - even for medium-sized combined heat and power plants. Otherwise the achievable segment would be reduced even further.

On the other hand, the use of CCS technology would be prudent in a future energy supply that only achieves limited gains in improving energy efficiency and further expanding renewable energies, and which shows only little structural change compared to the current situation. In that case, a completely different mix of renewable energies, compatible with an appropriate base-load operating CCS power plant fleet, would be necessary. Such a mix would not be suitable for compensating for fluctuating energies.

- The economic assessment of power plants with downstream CCS depends not only on the question of when the additional costs for $\mathrm{CO}_{2}$ capture are lower than the costs 
for acquiring $\mathrm{CO}_{2}$ allowances. It is more about determining relative cost effectiveness. To this end, the timing of competing climate protection options, such as renewable energies, must also be taken into account.

If fuel prices increase considerably and the cost of $\mathrm{CO}_{2}$ permits remains low, the generating costs of CCS-based natural gas and hard coal-fired power plants will be higher than with renewable energies from 2020. Lignite-fired CCS power plants will follow from 2025 (offshore wind/solar thermal energy) and 2030 (mix of renewable energies). Even in the case of very low increases in energy prices (but higher $\mathrm{CO}_{2}$ penalties), the additional costs incurred by CCS would be so high that renewable energies would remain competitive at the same time as in the high price scenario.

A driver of power generating costs is the decreasing utilisation period of fossil fired power plants. Bringing down the full load hours to $3,500 \mathrm{y} / \mathrm{h}$ increases the LCOE especially for lignite fired power plants while the costs of natural gas and coal fired power plants are dominated by the development of fuel prices and $\mathrm{CO}_{2}$ penalties. Nevertheless, also the net penalty of the overall power plant increases if a plant can only be operated in part load (Linnenberg and Kather 2011), which has not yet been considered in our calculation but which would further increase the LCOE.

It should be noted that no least cost model was applied but that the results were compared based on the LCOE at the power plants' stack. A least cost model would made sense if the political frame conditions for the power sector were rather open and no rates for renewable energies, energy efficiency matters and CHP would have been set as it is done by the European and the German energy policy.

Furthermore, the authors are aware that the issue of generating costs and the breakeven point between CCS-based power plants and renewable energies are no longer the only decisive factors from the viewpoint of investors. The approach applied so far has now been superseded by the stock market approach. In fact, the current price for electricity is determined by the stock market price, which, in turn, is dependent on the merit order of operational power plants. While research has subsequently proved that renewable energies have led to a decrease in electricity prices, despite their currently higher capital expenditure (since their marginal costs are virtually zero, unlike with expensive natural gas), it remains to be seen how they will influence CCS-based power plants.

- Only $\mathrm{CO}_{2}$ emissions released directly at the power plant are usually included in the debate on CCS as a climate protection option. However, a holistic approach needs to be applied to accurately assess the environmental impacts of CCS. Due to the additional consumption of primary energy caused by $\mathrm{CO}_{2}$ capture, $\mathrm{CO}_{2}$ emissions of the power plant process initially grow compared to a power plant process without $\mathrm{CO}_{2}$ capture. Consequently, the net quantity of $\mathrm{CO}_{2}$ avoided is considerably lower than the quantity of $\mathrm{CO}_{2}$ captured. Overall greenhouse gas emissions from CCS power stations will only be reduced in total by around 68 to 87 per cent, depending on the applied capture technology (up to 95 per cent in case of oxyfuel combustion). In addition, most capture processes would lead to a rise in non- $\mathrm{CO}_{2}$ emissions and other environmental factors due to the additional consumption of energy and chemicals used for $\mathrm{CO}_{2}$ capture. Hence, the $\mathrm{CO}_{2}$ mitigation potential of CCS needs to be reconciled with other environmental impacts - otherwise this technology in itself would neither beneficial nor sustainable. 
- The availability of long-term, stable storage sites will be pivotal in determining the potential of CCS. However, there are significant uncertainties surrounding the information about storage potentials. According to studies published between 1996 and 2009, the storage potential in Germany is estimated to be up to 44 billion tonnes, but crucial parameters used in these studies were either not published or not backed up adequately. This study presents a conservative estimate of German storage capacity in the sense of a minimum value to offer decision-makers from politics and industry a basis for planning. Considering that no formation water should be produced out of a saline aquifer and including a sweep-efficiency figure for hydrocarbon fields, the available storage capacity must be assumed to be limited to a total of 5 billion tonnes of $\mathrm{CO}_{2}$ (and an uncertainty fluctuation to 15 billion tonnes). The new study of the BGR confirms our maximum case although using the bottomup approach which allows for a much more detailed estimate based on the assessment of individual basins.

However, even according to this conservative storage capacity estimate, German storage formations would be sufficient to store the emissions captured from power plants in the scenario "Realistic I" (about 1.2 billion tonnes of $\mathrm{CO}_{2}$ ) until 2050. On the other hand, only the effective capacity was used as the basis in each comparison. The practical capacity, considering cost, infrastructure and acceptance constraints and therefore being generally lower than the effective capacity, would yield lower utilisation periods.

The analysis of existing studies and our calculation of a conservative storage capacity estimate show that there remain major uncertainties concerning the estimation of storage potential, particularly with regard to saline aquifers. A further outcome is that the variation of individual parameters has a considerable impact on the results of the calculation. However, it needs to be pointed out that not only existing, but also our own estimates, are based on rough data.

Regardless of the eventual realisable capacity, the question of whether this potential could be exploited quickly enough to enable a sufficiently fast deployment of CCS remains unanswered. It has not yet been explored whether there will be sufficient quantities of $\mathrm{CO}_{2}$ available in a short period of time, as might be expected from a constant flow from large-scale power plants, that can be injected into a storage site. For this reason, it is recommended that there is an investigation of the infrastructure required and the quantities of $\mathrm{CO}_{2}$ to be transported and injected, using various capacity scenarios for storage sites, coupled with emissions scenarios.

\subsection{CCS at large industrial sources and biomass combustion plants as alternative options}

So far, the German CCS debate has mainly focused on the power plant sector. However, recently, alternative applications are being increasingly considered. Especially research institutes, advisory bodies and NGOs are emphasising that capturing $\mathrm{CO}_{2}$ at industrial point sources and biomass-based energy production might outweigh the power sector in importance.

At the time being, $\mathrm{CO}_{2}$ emissions from industrial processes in Germany cumulate to 80 million tonnes (Öko-Institut 2009) compared to a total of large-point emissions of 388 million tonnes in 2007. Unlike CCS in the power plant sector, in the industrial context there are only few alternative options available that could assist in a further reduction of $\mathrm{CO}_{2}$ emissions. Among the available options for industrial $\mathrm{CO}_{2}$ 
mitigation are the usage of electricity and heat from renewable energies, improvements in process efficiency or a switch to alternative, more sustainable production processes. However, a significant share of emissions is process-immanent and cannot be avoided by applying measures such as renewable energies. Hence, CCS might play a significant role for achieving a substantial $\mathrm{CO}_{2}$ reduction in the industry sector. As a consequence, World Wide Fund for Nature (WWF) calls for mandating CCS in the German steel, cement and lime industries, contributing to an overall greenhouse gas mitigation by 95 per cent until 2050 (based on 1990) (WWF 2009). At a global scale, the International Energy Agency (IEA) projects that CCS at industrial emissions sources could contribute about 9 per cent to a 50 per cent emissions reduction (compared to the present level) by 2050 (IEA 2009). A similar outlook is suggested by the "Technology Roadmap CCS in Industry" which is currently under development by the United Nations Industrial Development Organization (UNIDO 2011).

The application of CCS in biomass plants (power and heat production as well as fuels) is of interest because "negative" $\mathrm{CO}_{2}$ emissions can be achieved. By separating the $\mathrm{CO}_{2}$ absorbed by plants during their growth, $\mathrm{CO}_{2}$ could not only be avoided, but extracted from the atmosphere, achieving negative net emissions. This could become relevant if it proves to be impossible to achieve existing reduction targets in other areas (Azar et al. 2010). As a potential "emergency" option, injecting $\mathrm{CO}_{2}$ from biomass-CCS operations (so-called BECCS) could be the prioritised usage for Germany's limited storage formations. Furthermore, biomass plants as well as industrial large-point sources have the added advantage that they generally create fewer emissions than large fossil-fired power stations, enabling the gases to be injected into smaller storage sites.

For both areas of application, industry and biomass, we see a large demand for assessment studies to explore the potentials, limitations and requirements for commercial use in Germany, but also all over Europe.

\subsection{Prospects of CCS in emerging countries}

Due to the economic and technical drawbacks of CCS, the position of focusing on CCS as a key mitigation option in the power plant sector while simultaneously retaining the current energy policy priorities (expansion of renewable energies and CHP, exhaustion of efficiency potentials) is becoming increasingly challenging. Although most of the results of the presented paper relate to Germany, similar conclusions may well be applicable for the rest of Europe, in view of several existing EU directives to expand renewable energies and increase energy efficiency.

Nevertheless, globally, CCS might be an important climate protection technology: coal-consuming countries such as China and India are increasingly moving centre stage into the debate, and these countries might not have the option of rapidly expanding renewable energies. For this reason, research, development and demonstration in the power plant sector continue to be important activities, as long as they are not at the expense of funding for renewable energies. However, the actual potential of CCS in key emerging economies is yet highly uncertain, especially with regard to national storage potentials and the potential of the countries' power plant mixes for integrating $\mathrm{CO}_{2}$ capture technologies. These questions are currently being explored in a further project of the Wuppertal Institute and Deutsche Gesellschaft für Internationale Zusammenarbeit (GIZ) GmbH. 


\section{Conclusions and outlook}

Our integrated assessment of CCS leads to the overall conclusion that under the given framework conditions in Germany there might not necessarily be a need to apply CCS in the German power plants sector. Even in case of ambitious climate protection targets, the current energy policy priorities (expansion of renewable energies and combined heat and power plants as well as enhanced energy productivity) result in a limited demand for CCS. In case that the large energy saving potential aimed for in the considered Lead Scenario 2008 can only partly be implemented, the rising gap in $\mathrm{CO}_{2}$ reduction could only be closed by setting up a CCS-maximum strategy. In this case, up to 22 per cent $(41 \mathrm{GW})$ of the totally installed load in 2050 could be based on CCS. Assuming an - in our view - more realistic scenario variant applying CCS to only $20 \mathrm{GW}$ or lower would not be sufficient to reach the envisaged climate targets in the electricity sector. On the other hand, the use of CCS technology would be prudent in a future energy supply that makes only moderate progress in increasing efficiency and further expanding renewable energies, and which shows only minor structural change compared to the current situation.

However, recently, alternative applications are being increasingly considered - that is the capture of $\mathrm{CO}_{2}$ at industrial point sources and biomass based energy production (electricity, heat and fuels). It is in these fields of application that we see a large demand for assessment studies to explore the potentials, limits and requirements for commercial use. Nevertheless, globally, CCS at power plants might be an important climate protection technology: coal-consuming countries emerging economies with greatly increasing electricity demand such as China and India are increasingly moving centre stage into the debate. Besides assessment studies on the potential for CCS (in power plants, industrial sites and biomass applications) the potential for renewable energies and their usage should be investigated as well. Although it often seems that these countries might not have the option of rapidly expanding renewable energies, the same might be true for CCS (even if considering the late commercial availability of CCS in industrialised countries). Taking into consideration the results of our study, similar investigations on the development and the integration of both, CCS and renewable energies, into the individual energy system structures of such countries would be reasonable.

\section{Acknowledgements}

The work this paper is based on (project RECCS Plus) was financially supported by the German Federal Ministry for the Environment, Nature Conservation and Nuclear Safety. We would like to greatly thank the reviewers for their comments and suggestions. Furthermore, we thank our colleagues Andrea Esken, Jochen Luhmann and Katja Pietzner as well as our subcontractors Lars Dietrich (Sozietät Wolter Hoppenberg) and Joachim Nitsch for their contributions to RECCS Plus, which we used for this article.

\section{References}

Azar C, Lindgren K, Obersteiner M, Riahi K, van Vuuren D P, Michel K, den Elzen G J, Möllersten K, Larson E D (2010) The feasibility of low $\mathrm{CO}_{2}$ concentration targets and the role of bio-energy with carbon capture and storage (BECCS). Climate Change 100:195-202. DOI 10.1007/s10584-010-9832-7 
Bauer C, Heck T, Dones R, Mayer-Spohn O, Blesl M (2008) Final report on technical data, costs, and life cycle inventories of advanced fossil power generation systems. Deliverable 7.2., NEEDS (New Energy Externalities Developments for Sustainability). http://www.needs-project.org/. Cited 6 Nov 2009

BMU (German Federal Ministry for the Environment, Nature Conservation and Nuclear Safety) (2008) Lead Study 2008 - Further development of the 'Strategy to increase the use of renewable energies' within the context of the current climate protection goals of Germany and Europe. http://www.bmu.de/english/renewable_energy/downloads/doc/42726.php.

Cited 22 Nov 2010

BMU (German Federal Ministry for the Environment, Nature Conservation and Nuclear Safety) (2011) Kabinett verabschiedet CCS-Gesetz. Press Release, Berlin, 13 April 2011

BMWi (German Federal Ministry of Economics and Technology) (2010) Energiedaten - Zahlen und Fakten - Nationale und Internationale Entwicklung. Berlin

Christensen N P, Holloway S (2004) GESTCO - Geological Storage of $\mathrm{CO}_{2}$ from Combustion of Fossil Fuel (Summary Report). Europäische Kommission, Brüssel

De Coninck H (2010) Advocacy for carbon capture could arouse public distrust. Letter to the Editor of http://www.ecn.nl/news/opinion/archive/advocacy-for-carbon-capture-couldarouse-public-distrust/. Cited 22 June 2011

DONG Energy (2008) Final report on offshore wind technology. EU-NEEDS. www.needs-project.org. Cited 08 Feb 2010

Ehlig-Economides C, Economides M J (2010) Sequestering carbon dioxide in a closed underground volume. J of Petroleum Science and Engineering 70:123130. DOI 10.1016/j.petrol.2009.11.002

Frankl P, Menichetti E, Raugei M (2008) Final report on technical data, costs and life cycle inventories of PV applications. Deliverable no 11.2-RS Ia, EU-NEEDS. www.needs-project.org. Cited 08 Feb 2010

Gerling J P (2008) Geologische $\mathrm{CO}_{2}$-Speicherung als Beitrag zur nachhaltigen Energieversorgung. Bergbau, Nr 10, pp472-475

Greenpeace (2008): False Hope - Why carbon capture and storage won't save the climate.

Full report. http://www.greenpeace.org/international/en/publications/reports/false-hope/. Cited 22 Nov 2010

Holloway S, Vincent C, Bentham M, Kirk K (2006) Top-down and bottom-up estimates of $\mathrm{CO}_{2}$ storage capacity in the UK sector of the southern North Sea basin. Environmental Geosciences 13:71-84. DOI 10.1306/eg.11080505015 
IEA (International Energy Agency) (2009) Technology roadmap - Carbon capture and storage. Paris

IEA GHG (IEA Greenhouse Gas R\&D Programme) (2009a) $\mathrm{CO}_{2}$ storage in depleted gas fields. Technical study No 2009/01. Stoke Orchard

IEA GHG (IEA Greenhouse Gas R\&D Programme) (2009b) Developments of storage coefficients for carbon dioxide storage in deep saline formations. Technical study No 2009/13. Stoke Orchard

Knopf S, May F, Müller C, Gerling J P (2010) Neuberechnung möglicher Kapazitäten zur $\mathrm{CO}_{2}$-Speicherung in tiefen Aquifer-Strukturen, Et 4(2010):7680

Koornneef J, van Keulen T, Faaij A, Turkenburg W (2008) Life cycle assessment of a pulverized coal power plant with post-combustion capture, transport and storage of $\mathrm{CO}_{2}$. Int $\mathrm{J}$ of Greenhouse Gas Control 4:448-467. DOI 10.1016/j.ijggc.2008.06.008

Linnenberg S, Kather A (2011) Implications of the Part-Load Behaviour of an Integrated Post-Combustion $\mathrm{CO}_{2}$ Capture Process for Hard-Coal-Fired Power plants. Book of extended abstracts of $2^{\text {nd }}$ Int Conf on Energy Process Engineering (ICEPE), Frankfurt

May F (2009) Aquifer storage - An option for emission reduction in Germany. Presentation at the IFP conference on Deep Saline Aquifers for Geological Storage of $\mathrm{CO}_{2}$ and Energy, Paris

May F, Müller C, Bernstone C (2005) How much $\mathrm{CO}_{2}$ can be stored in deep saline aquifers in Germany? VGB PowerTech 85(6):32-37

McLoughlin I, Dawso P (2003) The mutual shaping of technology and organisation 'Between Cinema and a Hard Place'. In: Preece D, Laurila J (eds) Technological change and organisational action, London

MIT (Massachsusetts Institute of Technology) (2007) The future of coal - Options for a carbon-constrained world. An interdisciplinary MIT Study, Massachusetts

Öko-Institut (2009) Regulierung von CO2-Abscheidung und -Ablagerung - Der Entwurf für das Kohlendioxid-Speicherungsgesetz (KSpG). Stellungnahme zum Entwurf für das Kohlendioxi-Speicherungsgesetz (KSpG) zur Anhörung des Ausschusses für Umwelt, Naturschutz und Reaktorsicherheit des 16. Deutschen Bundestages am 25. Mai 2009

Pehnt M, Henkel J (2009) Life cycle assessment of carbon dioxide capture and storage from lignite power plants. Int $\mathrm{J}$ of Greenhouse Gas Control 3:49-66. DOI 10.1016/j.ijggc.2008.07.001

Scheffknecht, G. (2005) Wege zum $\mathrm{CO}_{2}$-freien Kohlekraftwerk. 30. Sitzung DVVFachausschuss "Grundlagen und Anwendung". Werne, 16 Nov 2005

Schreiber A, Zapp P, Kuckshinrichs W (2009) Environmental assessment of German electricity generation from coal-fired power plants with amine-based carbon capture. Int J Life Cycle Assess 14:547-559. DOI 10.1007/s11367-009-0102-8 
TIAS (The Integrated Assessment Society) (2011) Defining Integrated Assessment. http://www.tias.uni-osnabrueck.de/. Cited 22 June 2011

UNIDO (United Nations Industrial Development Organization) (2011): Carbon Capture and Storage - Industrial Roadmap. http://www.unido.org/index.php?id=1000821. Cited 15 June 2011

van der Meer L G H, Yavuz F (2009) $\mathrm{CO}_{2}$ storage capacity calculations for the Dutch subsurface. Energy Procedia 1:2615-2622. DOI 10.1016/j.egypro.2009.02.028

van der Straaten R, Elewaut E, Koelewijn D, Baily H, Holloway S, Barbier J, Lindeberg E, Möller H, Gaida K (1996) Inventory of the $\mathrm{CO}_{2}$ storage capacity of the European Union and Norway. In: Holloway S (ed) Final report of the Joule II project No CT92-0031: The Underground Disposal of Carbon Dioxide. British Geological Survey, Nottingham, pp16-115

Vangkilde-Pedersen T, Vosgerau H, Willscher B, Neele F, van der Meer B, BossieCodreanu D, Wojcicki A, Nindre Y-M L, Kirk K, von Dalwigk I, Anthonsen K (2009) Capacity standards and site selection criteria. WP 4 Report D 26, EU Geocapacity, Denmark

Viebahn P (2011) Life Cycle Assessment for Power Plants with CCS. In: Stolten D, Scherer V (Eds) Efficient Carbon Capture for Coal Power Plants, Wiley-VCH Weinheim

Viebahn P, Lechon Y, Trieb F (2011) The potential role of concentrated solar power (CSP) in Africa and Europe - A dynamic assessment of technology development, cost development and life cycle inventories until 2050. Energy Policy 39:4420-4430

WI (Wuppertal Institute for Climate, Environment and Energy), DLR (German Aerospace Centre), PIK (Potsdam Institute for Climate Impact Research), ZSW (Centre for Solar Energy and Hydrogen Research) (2007) RECCS - Ecological, Economic and Structural Comparison of Renewable Energy Technologies (RE) with Carbon Capture and Storage (CCS) - an Integrated Approach. Study on behalf of the German Federal Ministry for the Environment, Nature Conservation and Nuclear Safety. http://www.wupperinst.org/projekte/proj/index.html?projekt id=25\&bid=155. Cited 12 Nov 2010

WI (Wuppertal Institute for Climate, Environment and Energy) (2010) RECCS Plus Comparison of Renewable Energy Technology with Carbon Dioxide Capture and Storage. Update and Expansion of the RECCS Study on behalf of the German Federal Ministry for the Environment, Nature Conservation and Nuclear Safety. http://www.wupperinst.org/projekte/proj/index.html?projekt_id=286\&bid=155. Cited 12 Nov 2010

WWF (World Wildlife Fund) (2009) Modell Deutschland - Klimaschutz bis 2050. Basel Berlin 
ZEP (Zero Emissions Platform) (2008) EU Demonstration Programme for $\mathrm{CO}_{2}$ Capture and Storage (CCS). ZEP's Proposal. European Technology Platform for Zero Emission Fossil Fuel Power Plants, Brussels 